\title{
The biphenyl-monitored effective size of unsaturated functional or fluorinated ortho substituents $\dagger+$
}

\author{
Renzo Ruzziconi, ${ }^{* a}$ Sara Spizzichino, ${ }^{a}$ Andrea Mazzanti, ${ }^{* b}$ Lodovico Lunazzi ${ }^{b}$ and Manfred Schlosser*c \\ Received 17th May 2010, Accepted 30th June 2010 \\ DOI: 10.1039/c0ob00136h
}

\begin{abstract}
The size of a series of typical substituents has been probed by dynamic NMR measurements of the barriers to aryl-aryl rotation of the corresponding biphenyls. The resulting $B$ values are meaningful because only mono-ortho substituted compounds were investigated and thus the results are not compromised by the non-additivity of multiple steric effects. On the basis of the chosen model system ethynyl and cyano groups were found to be slightly smaller than a phenyl ring. In contrast, vinyl and, in particular, formyl groups proved to be larger than phenyl. The latter difference is due to the loss of conjugation forces at the planar transition state. $\alpha$-Hydroxyhexafluoroisopropyl is slightly more bulky than tert-butyl. Pentafluorophenyl and trifluoromethoxy exhibit nearly the same effective size as phenyl and methoxy, respectively. Trifluoromethyl is somewhat smaller than isopropyl.
\end{abstract}

\section{Introduction}

It would be of obvious importance to create a reliable set of substituent parameters in order to predict and rationalize steric hindrance to chemical reactions. Such data should correlate reasonably well with the rates of standard transformations that are impeded to various degrees, but always in a well defined fashion, by non-bonded (intermolecularly collisional) interactions. Despite ingenious attempts this goal has not yet been achieved. ${ }^{1}$

In order to test this correlation, a new benchmark for chemical bulk is required. We believe that the biphenyl model would best serve this purpose. The ground state shape of biphenyl itself is twisted about the central aryl-aryl bond by some $44^{\circ}$ in order to alleviate the repulsion between the two pairs of ortho-hydrogen atoms (at the 2-/2'- and 6-/6'-positions). ${ }^{2-5}$ The twist angle increases to about $50^{\circ}$ if one fluorine atom occupies an ortho site and attains approximately $60^{\circ}$ with the more voluminous chlorine and bromine atoms or a methyl group., At the same time the energy required for forcing both aryl rings into coplanarity grows substantially.

This energy gap between the twisted ground state and the coplanar transition state structure can be experimentally assessed by variable-temperature ("dynamic") NMR measurements if a stereolabel Q* is introduced at the 3'-position in addition to the substituent $\mathrm{R}$ to be probed at the 2-position. If the auxiliary $3^{\prime}$ substituent harbors a pair of diastereotopic atoms or groups, e.g.

${ }^{a}$ Chemistry Department, University, Via Elce di Sotto 10, I-06100, Perugia, Italy.E-mail: ruzzchor@unipg.it; Fax: +39075 5855262; Tel: +39075 5855543

${ }^{b}$ Organic Chemistry Department "A. Mangini”, University of Bologna, Viale Risorgimento 4, I-40136, Bologna, Italy.E-mail: mazzand@ms.fci.unibo.it; Fax: +39051 2093654; Tel: +390512093633

'Institute of Chemical Sciences and Engineering, Ecole Polytechnique Fédérale (EPFL - BCh), CH-1015, Lausanne, Switzerland. E-mail: manfred.schlosser@epfl.ch; Tel:410216939351

$\dagger$ This article is dedicated to the memory of Professor Carlo Rosini (Università della Basilicata, Potenza) whose untimely demise means a permanent loss for the entire Italian stereochemical community.

† Electronic Supplementary Information (ESI) available: ${ }^{1} \mathrm{H}$ NMR spectra of 1-12. See DOI:10.1039/c0ob00136h/ the $\alpha$-hydrogens in methoxymethyl or the methyls in isopropyl, they resonate at different chemical shifts as long as the chirality of the twisted species is maintained on the NMR time scale. However, as soon as sufficient thermal energy is supplied, the chiral conformer enantiomerizes, i.e. is converted it into its mirror image by rotation about the central inter-ring axis until it passes through the coplanar transition state (Scheme 1). If this process occurs rapidly enough the two diastereotopic nuclei become magnetically equivalent (isochronous). Determination of the socalled coalescence temperature or, better, full line shape analysis provides the torsional barrier.

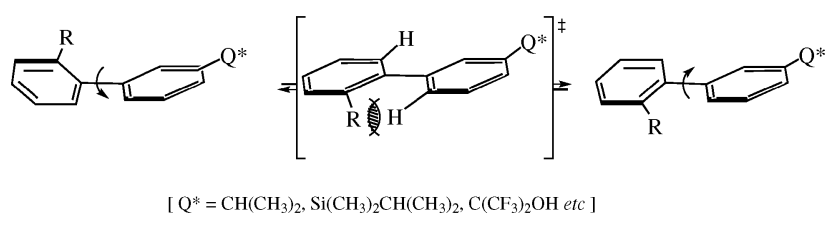

Scheme 1 Enantiomerization of a chiral biaryl conformer into its mirror image by passing through a coplanar transition state.

Our first attempts were aimed at determining the torsional barriers (" $B$ values", $B$ standing for biaryl) of methyl, ethyl, isopropyl, tert-butyl and, in addition, of the most common heterosubstituents, specifically the halogens, hydroxyl, alkoxy, nitro, amino, dimethylamino and trimethylammonio. ${ }^{6}$ Although most of the project was readily executed (Table 1 ), the torsional barriers of the 2-hydroxy and the 2-fluoro compounds proved to be too small to be measured when our standard diastereotopicity probes, isopropyl or isopropyldimethylsilyl, were employed. The minimal energy required for planarization of the unsubstituted biphenyl $\left(B 2.2^{4}\right.$ or rather $\left.2.0^{5}\right)$ was anyway far below experimental reach so that we had to resort to a computational result., 4

The problems encountered with the hydroxyl and fluorosubstituents were eventually solved by attaching $\alpha$-hydroxyhexafluoroisopropyl as a new diastereotopicity probe to the 3'position. The barriers found in that way amount to 5.4 and $4.4 \mathrm{kcal} / \mathrm{mol}$, respectively (Table 1). ${ }^{7}$ They can be broken down into the individual contributions or increments stemming from the 
Table $1 B$ values [in $\mathrm{kcal} / \mathrm{mol}$ ] of hydrogen-, alkyl-, nitrogen-, oxygenor halogen-bound substituents as determined by dynamic NMR measurements (in parentheses the numbers resulting from quantum chemical calculations) and the corresponding substituent increments $I^{2-\mathrm{R} / 2^{\prime} \mathrm{H}}$ [again in $\mathrm{kcal} / \mathrm{mol}$ ] (in parentheses the increments previously reported in ref. 8)

\begin{tabular}{lccc}
\hline $\mathrm{R}^{a}$ & $B^{b}$ & $B_{\text {calc }}{ }^{c}$ & $I^{2-\mathrm{R} / 2^{\prime}-\mathrm{H} d}\left(I^{\mathrm{lit}}\right)^{e}$ \\
\hline $\mathrm{H}$ & - & $2.0^{f}$ & $1.0(1.0)$ \\
$\mathrm{CH}_{3}$ & 7.4 & 7.1 & $6.4(9.7)$ \\
$\mathrm{C}_{2} \mathrm{H}_{5}$ & 8.7 & - & $7.7(-)$ \\
$\mathrm{CH}\left(\mathrm{CH}_{3}\right)_{2}$ & 11.1 & 11.1 & $10.1(12.5)$ \\
$\mathrm{C}\left(\mathrm{CH}_{3}\right)_{3}$ & 15.5 & 15.6 & $14.5(-)$ \\
$\mathrm{NH}_{2}$ & 8.1 & 8.4 & $7.1(9.6)$ \\
$\mathrm{N}\left(\mathrm{CH}_{3}\right)_{2}$ & 6.9 & 6.8 & $5.9(7.8)$ \\
$\oplus \mathrm{N}_{2}\left(\mathrm{CH}_{3}\right)_{3}$ & 18.1 & 18.2 & $17.1(-)$ \\
$\mathrm{NO}$ & 7.6 & 7.8 & $6.6(7.7)$ \\
$\mathrm{OH}$ & 5.4 & 5.3 & $4.4(6.5)$ \\
$\mathrm{OCH}$ & 5.6 & 4.5 & $4.6(6.4)$ \\
$\mathrm{OCH}_{2} \mathrm{OCH}_{3}$ & 5.7 & 6.1 & $4.7(-)$ \\
$\mathrm{F}$ & 4.4 & 4.3 & $3.4(4.6)$ \\
$\mathrm{Cl}$ & 7.7 & 7.3 & $6.7(9.1)$ \\
$\mathrm{Br}$ & 8.7 & 8.5 & $7.7(10.2)$ \\
$\mathrm{I}$ & 10.0 & 9.9 & $9.0(10.9)$
\end{tabular}

${ }^{a}$ Substituent at the 2-position of the biphenyl. ${ }^{b}$ Experimentally determined torsional barriers. ${ }^{6,7 ~ c}$ Computed barriers. ${ }^{d}$ Increments obtained by subtracting $1.0 \mathrm{kcal} / \mathrm{mol}^{5}$ from the corresponding $B$ value. ${ }^{e}$ Increments previously published (ref. 8). ${ }^{f}$ Ref. 5

repulsion between the 2-substituent $\mathrm{R}$ and the $2^{\prime}$-hydrogen atom $\left(I^{2-\mathrm{R} / 2^{\prime}-\mathrm{H}}\right)$ and the repulsion between the 6- and $6^{\prime}$-hydrogen atoms $\left(I^{6-\mathrm{H} / 6^{\prime}-\mathrm{H}}\right)$. The substituent-specific increments are thus obtained by subtracting $1.0 \mathrm{kcal} / \mathrm{mol}$ (representing the $I^{6-\mathrm{H} / 6^{6}-\mathrm{H}}$ interaction ${ }^{5}$ ) from the experimental torsional barriers. The discrepancy with previously reported $I^{2-\mathrm{R} / 2^{\prime}-\mathrm{H}}$ increments ${ }^{8}$ is substantial (e.g. $6.4 \mathrm{vs} 9.7$ for methyl, 4.3 vs 6.5 for hydroxyl and 3.3 vs 4.6 for fluorine). This is due to the fact that the values reported by Sternhell et al. ${ }^{8}$ are derived from $2,2^{\prime}$-substituted biphenyls to which a strict additivity rule was applied. As demonstrated, ${ }^{6,7}$ this additivity rule is not valid.

\section{Results}

The present work describes three significant extensions of the previous studies (Scheme 2). First, we determine the $B$ values of phenyl, ethenyl (vinyl), ethynyl (acetylide) and the azaanalogous cyano group (as probed with compounds 1-4). These substituents incorporate characteristic aromatic (one and a half bond), olefinic (double bond) and acetylenic (triple bond) structural entities. Next, we turn to the three oxidation levels of carbon-oxygen functional groups, especially the hydroxymethyl, formyl and carboxy groups and include also the ester unit methoxycarbonyl (as probed with compounds 5-8). Finally, we

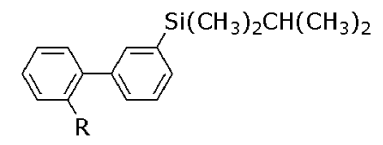
1: $\mathrm{R}=\mathrm{C}_{6} \mathrm{H}_{5}$
5: $\mathrm{R}=\mathrm{CH}_{2} \mathrm{OH}$
9: $\mathrm{R}=\mathrm{C}_{6} \mathrm{~F}_{5}$
2: $\mathrm{R}=\mathrm{CH}=\mathrm{CH}_{2}$
6: $\mathrm{R}=\mathrm{CH}=\mathrm{O}$
10: $\mathrm{R}=\mathrm{C}\left(\mathrm{CF}_{3}\right)_{2} \mathrm{OH}$
3: $\mathrm{R}=\mathrm{C} \equiv \mathrm{CH}$
7: $\mathrm{R}=\mathrm{COOH}$
11: $\mathrm{R}=\mathrm{CF}_{3}$
4: $\mathrm{R}=\mathrm{C} \equiv \mathrm{N}$
8: $\mathrm{R}=\mathrm{COOCH}_{3}$
12: $\mathrm{R}=\mathrm{OCF}_{3}$

Scheme 2 The scope of the present investigation: examining the model compounds 1-12. focus on four typical fluorine-containing groups, the pentafluorophenyl, $\alpha$-hydroxyhexafluoroisopropyl, trifluoromethyl and trifluoromethoxy substituents (as probed with compounds 9-12).

The ${ }^{1} \mathrm{H}$ and ${ }^{13} \mathrm{C}$ NMR spectra were recorded in the same manner as previously described. ${ }^{6}$ A typical series of spectra taken of 2-ethynyl-3'-(isopropyldimethylsilyl)biphenyl (3) is reproduced below (Fig. 1).

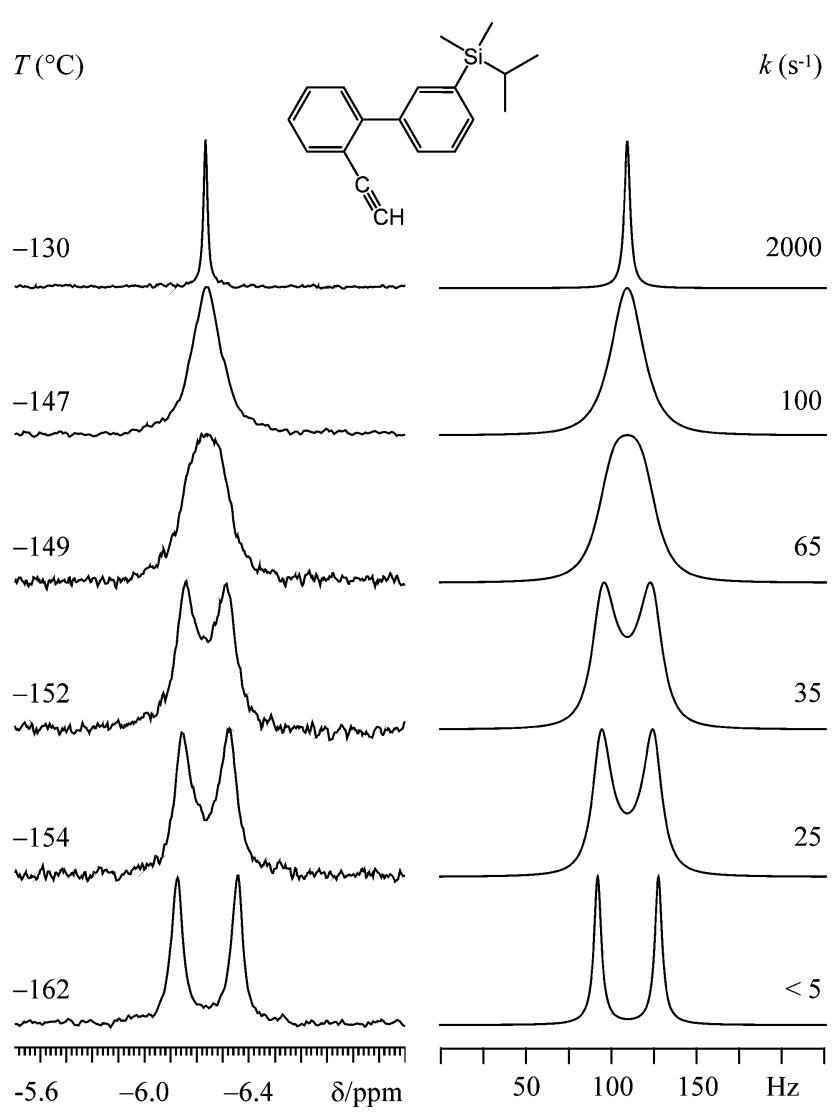

Fig. 1 Compound 3: Temperature dependence of the ${ }^{13} \mathrm{C}$ signal of the silicon-bound methyl groups (recorded at $150.8 \mathrm{MHz}$ in a $3: 1 \mathrm{v} / \mathrm{v}$ mixture of chlorodifluoromethane and dichlorofluoromethane) on the left, and the simulated spectra with the corresponding rate constants on the right.

The NMR spectra of compounds 1-2 and 4-12 were recorded analogously. Sample temperatures were varied until the decoalescence temperature was detected unequivocally in each case. Line shape analysis and spectra simulation provided the activation energies of the aryl-aryl rotation. These numbers are listed as substituent-specific $B$ values along with the computed barriers and the substituent increments $I^{2-\mathrm{R} / 2^{\prime}-\mathrm{H}}$ (Table 2). The latter increments were obtained by subtracting $1.0 \mathrm{kcal} / \mathrm{mol}$ (i.e. the steric repulsion approximately existing between one coplanar pair of $o$ - and $o^{\prime}-$ hydrogen atoms) from the $B$ value (i.e. the experimental torsional energy) and thus represent the repulsive force a substituent $\mathrm{R}$ located at the 2-position experiences from a coplanar $o$-hydrogen atom facing it on the neighboring ring.

The synthesis of most model compounds relied on the SuzukiMiyaura coupling method. ${ }^{9,10}$ Such reaction are known to be straightforward. The fundamental choice is to place the 2-R substituent next to the dihydroxyboryl group and to let the 
Table $2 B$ values (in $\mathrm{kcal} / \mathrm{mol}$ ) of aromatic, olefinic, (aza)acetylenic, carbon-oxygen functional and fluorine-containing substituents as assessed by dynamic NMR measurements of 2-R substituted biphenyls (in parentheses, for comparison, the numbers obtained by quantum chemical calculations) and the corresponding substituent increments $I^{2-\mathrm{R} / 2^{\prime}-\mathrm{H}}$.

\begin{tabular}{llrrc}
\hline $\mathrm{Cpd}^{a}$ & $2-\mathrm{R}$ & $B^{b}$ & $B_{\text {calc }}{ }^{c}$ & $I^{2-\mathrm{R} / 2^{\prime}-\mathrm{H} d}\left(I^{\mathrm{lit}}\right)^{e}$ \\
\hline $\mathbf{1}$ & $\mathrm{C}_{6} \mathrm{H}_{5}$ & 7.5 & 7.4 & $6.5(7.9)$ \\
$\mathbf{2}$ & $\mathrm{CH}=\mathrm{CH}_{2}$ & 8.2 & 8.5 & $7.5(-)$ \\
$\mathbf{3}$ & $\mathrm{C} \equiv \mathrm{CH}$ & 6.0 & 5.3 & $5.0(-)$ \\
$\mathbf{4}$ & $\mathrm{C} \equiv \mathrm{N}$ & 5.9 & 5.2 & $4.9(6.1)$ \\
$\mathbf{5}$ & $\mathrm{CH}$ & 7.9 & 7.8 & $6.9(9.8)$ \\
$\mathbf{6}$ & $\mathrm{CH}=\mathrm{O}$ & 10.2 & 11.0 & $9.2(-)$ \\
$\mathbf{7}$ & $\mathrm{COOH}$ & 7.7 & 8.5 & $6.7(-)$ \\
$\mathbf{8}$ & $\mathrm{COOCH}$ & 7.7 & 8.3 & $6.7(8.2)$ \\
$\mathbf{9}$ & $\mathrm{C}_{6} \mathrm{~F}_{5}$ & 7.7 & 8.1 & $6.7(-)$ \\
$\mathbf{1 0}$ & $\mathrm{C}_{3}\left(\mathrm{CF}_{3}\right)_{2} \mathrm{OH}$ & 16.5 & 16.9 & $15.5(-)$ \\
$\mathbf{1 1}$ & $\mathrm{CF}_{3}$ & 10.5 & 9.2 & $9.5(12.1)$ \\
$\mathbf{1 2}$ & $\mathrm{OCF}_{3}$ & 5.5 & 4.8 & $4.5(-)$
\end{tabular}

${ }^{a}$ Numbering as in Scheme 2. ${ }^{b}$ Barriers to aryl-aryl rotation ( $B$ values) [in $\mathrm{kcal} / \mathrm{mol}] .{ }^{c}$ Computed barriers (see Experimental Section) [in $\mathrm{kcal} / \mathrm{mol}$ ]. ${ }^{d}$ Increments for the $2-\mathrm{R} / 2^{\prime}$ - $\mathrm{H}$ repulsion alone by deduction of 1.0 (representing the $2-\mathrm{H} / 2^{\prime}-\mathrm{H}$ interaction) from the $B$ values [in $\mathrm{kcal} / \mathrm{mol}] .{ }^{e}$ Increments previously published (ref. 8). ${ }^{f}$ Value obtained by monitoring the ${ }^{1} \mathrm{H}$ signal of the silicon-bonded methyls of $\mathrm{Q}^{*}$ and from the ${ }^{19} \mathrm{~F}$ spectra of the $\mathrm{CF}_{3}$ groups.

bromoarene or iodoarene component bear the $3-\mathrm{Q}^{*}$ diastereotopicity probe or to opt for the opposite combination.

On top of that, 2-bromo-3'-(isopropyldimethylsilyl)biphenyl has been designated to act as a key intermediate in the preparation of numerous other 2-R-substituted biphenyls (see below). Its palladium-catalyzed coupling with phenylboronic acid turned out to offer the most convenient access to 2-phenyl3'-(isopropyldimethylsilyl)biphenyl (3'-isopropyldimethylsilyl$1,1^{\prime} ; 2^{\prime}, 1^{\prime}$-terphenyl, 1) as a practical comparison has revealed (Scheme 3). Biphenyl 1 can also be readily accessed by coupling 3-(isopropyldimethylsilyl)phenylboronic acid with 2-bromobiphenyl or by coupling biphenyl-2-ylboronic acid with 1-bromo-3-(isopropyldimethylsilyl)benzene (Scheme 3).

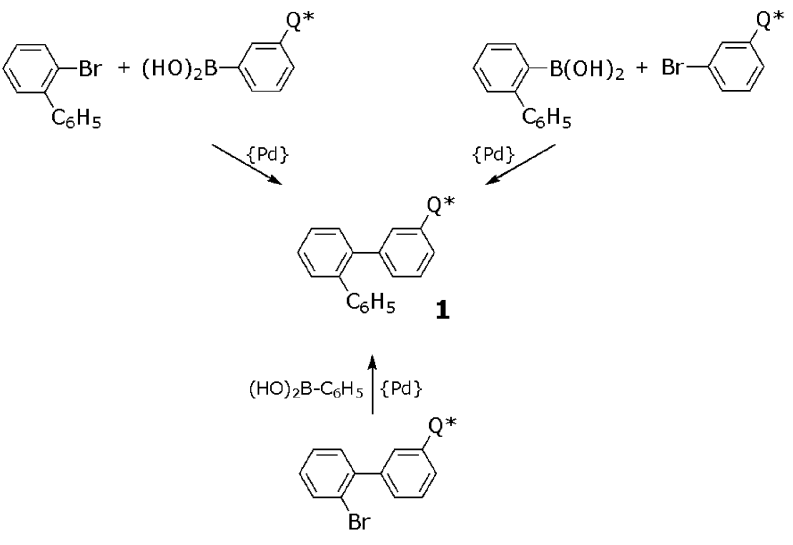

$\left[\mathrm{Q}^{*}=\mathrm{Si}\left(\mathrm{CH}_{3}\right)_{2} \mathrm{CH}\left(\mathrm{CH}_{3}\right)_{2}\right]$

Scheme 3 Three routes leading to 2-phenyl-3'-(isopropyldimethylsilyl)biphenyl (1).

The 2-vinyl and 2-cyano biaryls $2(54 \%)$ and $4(60 \%)$ were prepared by palladium-catalyzed condensation of 2-bromostyrene and 2-bromobenzonitrile with 3-(isopropyldimethyl- silyl)phenylboronic acid (Scheme 4). The latter building block was made from 1,3-dibromobenzene in two operational steps (Scheme 4).

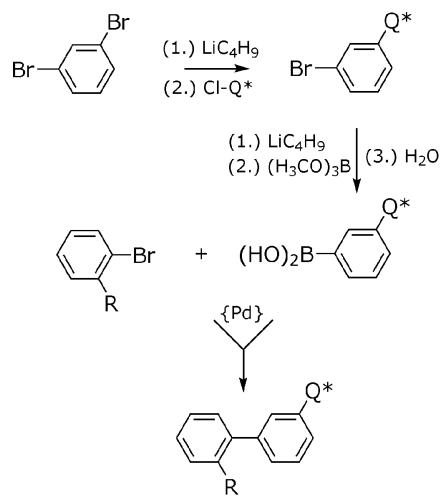

$\left[\mathrm{R}=\mathrm{CH}=\mathrm{CH}_{2}, \mathrm{C} \equiv \mathrm{N}\right]$

$\left[\mathrm{Q}^{*}=\mathrm{Si}\left(\mathrm{CH}_{3}\right)_{2} \mathrm{CH}\left(\mathrm{CH}_{3}\right)_{2}\right]$

Scheme 4 Biaryls 2 and 4 , prepared by palladium-catalyzed coupling of 2-R-substituted bromobenzenes with 3-(isopropyldimethylsilyl)phenylboronic acid.

As triple bonds tend to be labile under Suzuki-Miyaura conditions, the 2-ethynyl biaryl $\mathbf{3}$ was made according to a Negishi-like protocol (Scheme 5). ${ }^{11}$ 2-Ethynyl-3'-(isopropyldimethylsilyl)biaryl (3) was obtained from 1-bromo-2-(trimethylsilylethynyl)benzene in $72 \%$ yield.

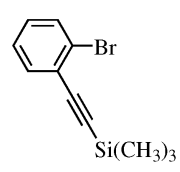

$$
\downarrow^{(1 .) \mathrm{LiC}_{4} \mathrm{H}_{9}}
$$

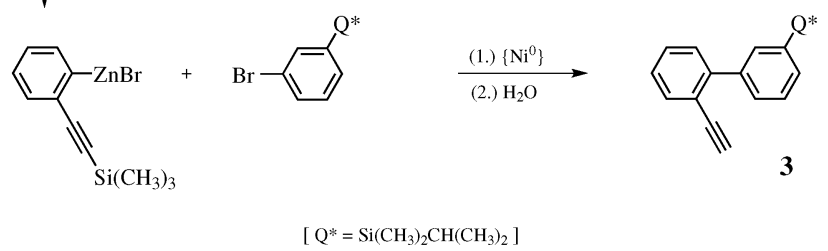

Scheme 5 2-Ethynyl-3'-(isopropyldimethylsilyl)biphenyl (3), prepared by nickel-catalyzed coupling of 2-(2-trimethylsilyl)ethynylphenylzinc bromide with 1-bromo-3-(isopropyldimethylsilyl)benzene.

The inverse combination (with respect to Scheme 4) of the Suzuki-Miyaura components, 2-R-substituted phenylboronic acids coupled with 1-bromo-3-(isopropyldimethylsilyl)benzene, had been explored previously ${ }^{6}$ in an attempt to get hold of large amounts of 2-bromo-3'(isopropyldimethylsilyl)biphenyl $(2-\mathrm{R}=\mathrm{Br})$. Unfortunately this product, conceived to act as a turntable intermediate on the way to whole a series of model compounds, was almost more rapidly consumed than formed. Therefore, we had to resort to the equally unclean coupling between 1,2-dibromobenzene and 3-(isopropyldimethylsilyl)phenylboronic acid. ${ }^{6}$ A satisfactory result was now achieved by merely replacing the coupling unit 1-bromo-3-(isopropyldimethylsilyl)benzene by its iodo analog. 2-Bromo-3'(isopropyldimethylsilyl)biphenyl was isolated in $89 \%$ yield. It was 
readily converted (see Scheme 6) by consecutive halogen/metal permutation and electrophilic trapping into the biaryls 5 (directly with paraformaldehyde or indirectly by reduction of aldehyde 6 with sodium borohydride, 95\%), 6 (with dimethylformamide, after hydrolysis, $62 \%$ ), 7 (with dry ice, after neutralization, $63 \%$ ), 10 (with hexafluoroacetone, $67 \%$ ) and 9 (with hexafluorobenzene, $57 \%)$. The methyl ester $8(89 \%)$ was obtained by treatment of the carboxylic acid 7 with ethereal diazomethane (Scheme 6).

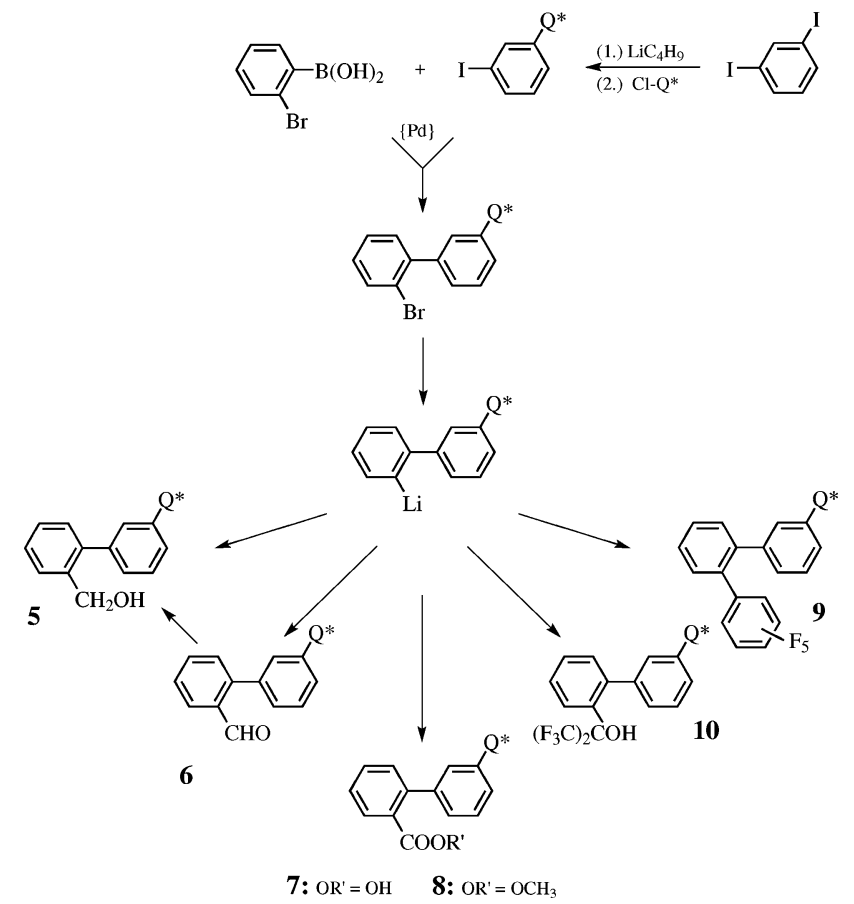

Scheme 6 Access to the biaryls 5-10 by palladium-catalyzed coupling of 2-bromo-phenylboronic acid with 1-iodo-3-(isopropyldimethylsilyl)benzene followed by halogen-metal permutation and electrophilic trapping.

1-Bromo-3-(isopropyldimethylsilyl)benzene can be employed without problems for the coupling with arylboronic acids as long as the latter do not bear bromo or iodo substituents. In this way, clean reactions were performed affording 2-formyl (6), 2trifluoromethyl (11) and 2-trifluoromethoxy (12) substituted 3'(isopropyldimethylsilyl)biphenyls in $91 \%, 80 \%$ and $88 \%$ yield, respectively (Scheme 7).

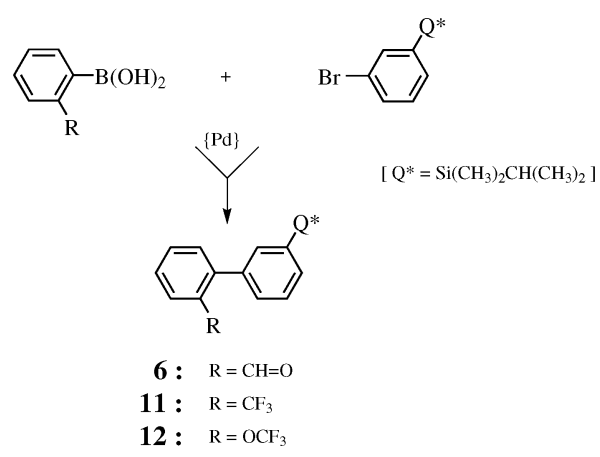

Scheme 7 Biaryls 6, 11 and $\mathbf{1 2}$ by palladium-catalyzed coupling of 2-R-substituted phenylboronic acids with 1-bromo-3-(isopropyldimethylsilyl)benzene.

\section{Discussion}

No set of parameters is without built-in bias. Inequalities inherent in the reference system will sooner or later manifest themselves and delude intuition. The resulting discrepancy between expectation and reality provides new insight. Whatever test applied, a dimethylamino group bound to a saturated counterpart will score as more voluminous than a simple amino group. But the latter appears to be evidently "bigger" when attached to the ortho position of a biaryl. The reason is a consequence of differences in spatial orientation. The amino group $(B$ 8.1) has its lone pair aligned in parallel with the adjacent aromatic $\pi$-cloud at the twisted ground state. The corresponding energy of conjugation is lost at the coplanar transition state where steric hindrance forces the amino group into a skew position. ${ }^{6}$ In contrast, the dimethylamino (B 6.9) entity is twisted out-of-resonance with respect to the adjacent aryl ring in both the ground state and the transition state. Therefore, as there is no conjugation energy from the beginning there is no penalty for sacrificing it either. ${ }^{6}$ The dependence of conjugation on conformation is without doubt the origin of the higher $B$ values of vinyl ( $B$ 8.2) and formyl $(B$ 10.2) in comparison with phenyl ( $B$ $7.5)$ and hydroxymethyl (B 7.9), respectively.

Furthermore, noteworthy are the seemingly identical spacial requirements of methyl (B 7.4) and phenyl (B 7.5). This suggests a perpendicular orientation of the (unsubstituted) 2-phenyl group with respect to the coplanar biaryl unit at the torsional transition state. In this geometry the distance of the $2^{\prime}$-hydrogen atom to the 2-methyl group is indeed a bit longer than that to the center of the 2-phenyl ring. These changes of the conformational landscape are indeed nicely reproduced by DFT calculations (Fig. 2 and Experimental). The barrier to 2-phenyl/biphenyl rotation has been previously derived from the dynamic NMR study of 3,3'diisopropyl-1,1'; $2^{\prime}, 3^{\prime \prime \prime}$-terphenyl. ${ }^{12}$ The number reported $(B$ 7.7) coincides with the newly found one $(B$ 7.5) within the limits of error $( \pm 0.2 \mathrm{kcal} / \mathrm{mol}$, mainly due to uncertainty in the temperature determination).
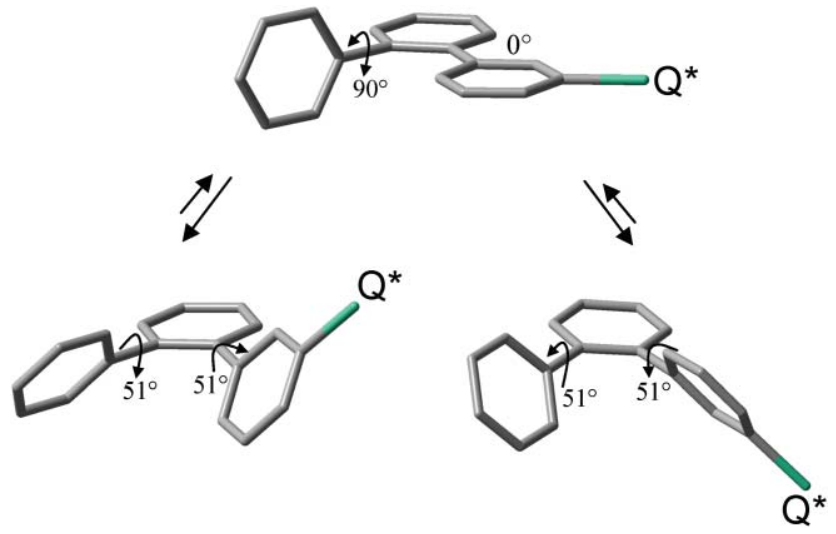

Fig. 2 Torsional ground state (structures in the bottom line) and transition state (structure in the top line) of 3-(isopropropyldimethylsilyl)-1,1'; $2^{\prime}, 3^{\prime \prime \prime}$-terphenyl $\left[\mathrm{Q}^{*}=\mathrm{Si}\left(\mathrm{CH}_{3}\right)_{2} \mathrm{CH}\left(\mathrm{CH}_{3}\right)_{2}\right]$ : correlated motion of the two lateral aryl rings.

The last four model compounds feature prominent oligofluoro substituents. The famous quote "...trifluoromethyl is at least as big as isopropyl..."13 has stirred up emotions. The judgment appears to be based on a somewhat uncritical appraisal of the pertinent 
$A$ values ${ }^{14-16}$ (Scheme 8), the energy differences between the axial and equatorial conformers of (trifluoromethyl)cyclohexane ( $A 2.4$ $-2.5)^{17}$ and isopropylcyclohexane $\left.(A 2.15)\right)^{14,18}$ The inward leaning $\mathrm{C}-\mathrm{H}$ bond of an axial methyl group experiences far more repulsion by the axial hydrogens at the homovicinal ring position than the compressed lone pairs of an axial fluorine $(A 0.15)$ do (Scheme 8). Unlike tert-butyl ( $A 4.90)$, isopropyl $(A 2.15)$ can rotate all its methyl groups outward, away from the cyclohexane chair, even if this goes at the expense of an increase in order (i.e. an entropy decrease). If trifluoromethyl is the axial substituent, inevitably one of its halogen atoms collides with the axial hydrogen atoms at the 3- and 5-position of the ring. Our $B$ values rank $\mathrm{CF}_{3}(B$ 10.5) a little smaller than $\mathrm{CH}\left(\mathrm{CH}_{3}\right)_{2}$ (B 11.1) but clearly bigger than $\mathrm{CH}_{3}\left(B\right.$ 7.4). By the way, the $\mathrm{F}-\mathrm{C}-\mathrm{F}$ angles of $106.9^{\circ}$ in benzotrifluoride ${ }^{19}$ are somewhat narrower than the $\mathrm{H}-\mathrm{C}-\mathrm{H}$ angles of $108.1^{\circ}$ in toluene. ${ }^{20}$

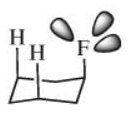

A 0.15

$B 4.3$

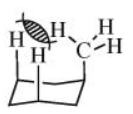

A 1.70

$B 7.4$

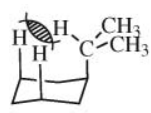

A 2.15

$B 11.1$

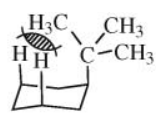

A 4.90

$B 15.5$

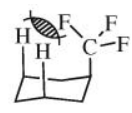

A 2.35 B 10.5
Scheme $8 A$ values and, for comparison, $B$ values of fluorine, methyl, isopropyl, tert-butyl and trifluoromethyl.

Replacing the 2-phenyl substituent (in compound 1) by a pentafluorophenyl entity (in compound 9) should raise the barrier to the corresponding aryl-aryl rotation only moderately (the torsional activation energy of $2,2^{\prime}$-difluorobiphenyl is approximately $4.8 \mathrm{kcal} / \mathrm{mol}^{4}$ ) and increase that of the 2-R-phenyl $/ 3^{\prime} \mathrm{Q}^{*}$-phenyl rotation hardly at all. These assumptions were confirmed by the experiment (Table 2).

As evidenced by its impressive $B$ value of $16.5, \alpha-$ hydroxyhexafluoroisopropyl undoubtedly belongs to the very bulky substituents. In drug design it may qualify as a metabolically stable mimic of the similarly voluminous tert-butyl $(B 15.5)$ or tertamyl (1,1-dimethylpropyl) group.

Trifluoromethoxy is a substituent that receives growing attention in the life sciences arena. ${ }^{21}$ Having virtually the same dimensions as methoxy ( $B$ 5.6) it belongs to the smallest substituents in our present collection (Table 2, compound 12, B 5.5). Anisole and (trifluoromethoxy)benzene nevertheless exhibit some structural differences (Scheme 9). Whereas all heavy atoms occupy the same plane at the ground state of anisole, its trifluorinated analog favors the orthogonal orientation of the $\mathrm{O}-\mathrm{CF}_{3}$ group with respect to the ring plane. ${ }^{22,23}$ This change in conformational preference may be merely caused by the steric interaction between an ortho$\mathrm{C}-\mathrm{H}$ bond and the $\mathrm{CF}_{3}$ substituent (being bigger than $\mathrm{CH}_{3}$ ). Alternatively, it may mirror a stereoelectronic effect (the electronwithdrawing halogens impeding an effective conjugation between the $\mathrm{OCF}_{3}$ oxygen and the aromatic $\pi$-sextet).
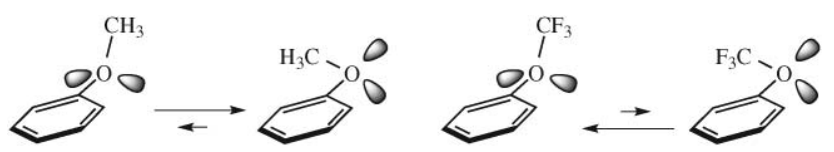

Scheme 9 Relative populations of anisole and (trifluoromethoxy)benzene conformations.
Fluorine is a favorite tool for engineering molecular properties. For this reason it plays a privileged role in current research focusing on new pharmaceuticals, agrochemicals and high-performance materials. ${ }^{240}$ Scaling the size of common fluorinated substituents may help to promote such practical applications.

\section{Experimental section}

\section{Generalities}

Starting materials were purchased from Aldrich-Fluka $(\mathrm{CH}-$ 9479 Buchs) and Apollo Scientific (UK-SK62QR Stockport) unless literature sources or details of the preparation are given. All commercial reagents were used without further purification, except trimethyl borate which was distilled before use.

Air and moisture sensitive compounds were stored in Schlenk tubes or Schlenk burettes. They were protected by, and handled under, an atmosphere of $99.995 \%$ pure nitrogen, using appropriate glassware. Tetrahydrofuran and diethyl ether were stored over potassium hydroxide pellets in the presence of cuprous chloride, from which they were distilled, before being redistilled from sodium wire after the characteristic blue color of in situ generated sodium biphenyl ketyl (benzophenone-sodium "radical anion") had been found to persist. "Petroleum ether" refers to an alkane fraction having a boiling range of $40-60{ }^{\circ} \mathrm{C}$.

The temperature of liquid nitrogen/methanol and dry ice/methanol baths are consistently indicated as $-90{ }^{\circ} \mathrm{C}$ and $-75^{\circ} \mathrm{C}$, respectively, that of ice baths as $0^{\circ} \mathrm{C}$. Ambient temperature ("room temperature") translates into $+25^{\circ} \mathrm{C}$ although the real temperature in the laboratory varies between 22 and $26^{\circ} \mathrm{C}$. Melting ranges (m.p.) given were found to be reproducible after resolidification unless decomposition ("dec.") is specified. The temperature readings were corrected using a calibration curve established with authentic standards.

${ }^{1} \mathrm{H},{ }^{13} \mathrm{C}$ and ${ }^{19} \mathrm{~F}$ NMR spectra were recorded at $400,100.6$ and $376.5 \mathrm{MHz}$, respectively, samples having been dissolved in deuterochloroform. Chemical shifts $(\delta)$ are given in ppm relative to the internal standards tetramethylsilane and trichlorofluoromethane. IR spectra were taken of chloroform solutions in the $4000-625 \mathrm{~cm}^{-1}$ frequency range, mass spectra by electron impact fragmentation at $70 \mathrm{eV}$ ionization potential and $200{ }^{\circ} \mathrm{C}$ source temperature.

The purity of all final products was testified by elemental analyses (performed by the Redox Company in Monza and by Dr E. Solari at the Analytic Services of EPFL-ISIC) and by gas chromatography using two capillary columns of different polarity $(30 \mathrm{~m} \times 0.35 \mathrm{~mm} \times 0.25 \mu \mathrm{m}$ DB $5 \mathrm{MS}[5 \%$ phenylmethylpolysiloxane] and $30 \mathrm{~m} \times 0.35 \mathrm{~mm} \times 0.25 \mu \mathrm{m}$ DB23 [50\% cyanopropylmethylpolysiloxane]). This holds also for the highly (17-27\%) fluorinated products 9-12, the elemental analyses of which deviated from the calculated numbers considerably more than by the ordinary error limits (of $\pm 0.3 \%$ ). This happens often with samples containing more than $10 \%$ of fluorine in weight.

\section{Intermediates and Final Products}

(3-Iodophenyl)isopropyldimethylsilane. At $-95^{\circ} \mathrm{C}$ (liquid air/ methanol bath), butyllithium $(9.10 \mathrm{mmol})$ in hexanes $(5.7 \mathrm{~mL})$ and, 5 min later, chloroisopropyldimethylsilane $(2.5 \mathrm{~g}, 18 \mathrm{mmol})$ 
were added to a solution of 1,3-diiodobenzene ( $3.3 \mathrm{~g}, 14 \mathrm{mmol})$ in dry tetrahydrofuran $(30 \mathrm{~mL})$. After $2 \mathrm{~h}$ at $-75^{\circ} \mathrm{C}$ the mixture was poured into water $(0.10 \mathrm{~L})$ and extracted with diethyl ether $(3 \times 40 \mathrm{~mL})$. The combined extracts were dried with sodium sulfate. After evaporation of the solvent, distillation of the residue afforded a pale yellow liquid product; $2.50 \mathrm{~g}(90 \%)$; b.p. 119 $121{ }^{\circ} \mathrm{C} / 0.2 \mathrm{mmHg} .{ }^{1} \mathrm{H}$ NMR: $\delta 7.67(\mathrm{~d}, J=7.9 \mathrm{~Hz}, 1 \mathrm{H}), 7.43(\mathrm{~d}$, $J=7.3 \mathrm{~Hz}, 1 \mathrm{H}), 7.08(\mathrm{t}, J=7.4 \mathrm{~Hz}, 1 \mathrm{H}), 0.93(\mathrm{~s}, 7 \mathrm{H}), 0.22(\mathrm{~s}, 6$ H). ${ }^{13} \mathrm{C}$ NMR: $142.4,142.3,137.6,132.7,129.6,95.4,17.4$ (2 C), 13.6, -5.5 (2 C). MS: $m / z$ (\%) $304\left(\mathrm{M}^{+}, 36\right), 289$ (2), 261 (100), 247 (11), 134 (23), 119 (55), 43 (17). Anal.: calcd for $\mathrm{C}_{11} \mathrm{H}_{17} \mathrm{ISi}$ (304.24) C, 43.43; H, 5.63; found: C, 43.74; H, 6.06 .

2-Bromo-3'-(isopropyldimethylsilyl)biphenyl ${ }^{6}$. Ethanol $\quad(5.0$ $\mathrm{mL}$ ), benzene $(10 \mathrm{~mL})$, (3-iodophenyl)isopropyldimethylsilane $(0.50 \mathrm{~g}, 1.6 \mathrm{mmol}), 2.0 \mathrm{M}$ aq. potassium carbonate $(1.6 \mathrm{~mL})$, tetrakis[triphenylphosphine]palladium $(0)(0.040 \mathrm{~g}, 0.034 \mathrm{mmol})$ were added consecutively to 2 -bromophenylboronic acid $(0.36 \mathrm{~g}$, $1.8 \mathrm{mmol})$. The mixture was kept at reflux for $3 \mathrm{~h}$. After cooling, water was added and the mixture was extracted with diethyl ether $(20 \mathrm{~mL})$. After drying with sodium sulfate the solvent was evaporated. Elution of the residue from silica gel $(0.12 \mathrm{~L})$ with petroleum ether afforded a colorless oil; $0.49 \mathrm{~g} \mathrm{(90 \% );} \mathrm{b.p.}$ 171-173 ${ }^{\circ} \mathrm{C} / 0.2 \mathrm{mmHg} .{ }^{1} \mathrm{H}$ NMR: $\delta 7.67(\mathrm{~d}, J=8.0 \mathrm{~Hz}, 1 \mathrm{H})$, $7.55(\mathrm{~s}, 1 \mathrm{H}), 7.52(\mathrm{~d}, J=6.7 \mathrm{~Hz}, 1 \mathrm{H}), 7.4(\mathrm{~m}, 4 \mathrm{H}), 7.20(\mathrm{ddd}, J=$ 9.1, 7.3, 2.4, $1 \mathrm{H}), 0.97$ (s, $7 \mathrm{H}), 0.27(\mathrm{~s}, 6 \mathrm{H}) \mathrm{ppm} .{ }^{13} \mathrm{C}$ NMR: $\delta$ 142.8, 140.1, 138.3, 135.0, 133.1, 133.1, 131.3, 129.6, 128.6, 127.3, 127.2, 122.7, $17.6(2 \mathrm{C}), 13.8,-5.3(2 \mathrm{C}) \mathrm{ppm}$. MS : $\mathrm{m} / \mathrm{z}(\%)=$ $334\left(\mathrm{M}^{+}+1,2\right), 332\left(\mathrm{M}^{+}-1,2\right), 291(100), 289$ (100), $211(14)$, 152 (35), 43 (33). Anal.: calcd for $\mathrm{C}_{17} \mathrm{H}_{21} \mathrm{BrSi}$ (333.34) C, 61.25; $\mathrm{H}, 6.35$; found: $\mathrm{C}, 61.30 ; \mathrm{H}, 6.80$.

\begin{abstract}
3'-(Isopropyldimethylsilyl)-2-phenylbiphenyl [3-(isopropyldimethylsilyl)-1, $\mathbf{1}^{\prime} ; \mathbf{2}^{\prime}, \mathbf{1}^{\prime \prime}$ terphenyl] (1). Ethanol (3.0 $\left.\mathrm{mL}\right)$, benzene $(5.0 \mathrm{~mL}), 2$-bromo-3'-(isopropyldimethylsilyl)biphenyl $(0.14 \mathrm{~g}, 0.42 \mathrm{mmol}), 2.0 \mathrm{~m}$ aq. potassium carbonate $(1.6 \mathrm{~mL})$, tetrakis[triphenylphosphine]palladium $(0)(0.040 \mathrm{~g}, 0.034 \mathrm{mmol})$ were added consecutively to phenyl boronic acid $(0.056 \mathrm{~g}$, $0.46 \mathrm{mmol})$. After refluxing the mixture for $3 \mathrm{~h}$, water $(10 \mathrm{~mL})$ was added and the mixture was extracted with diethyl ether $(20 \mathrm{~mL})$. The dried organic layer was evaporated. Elution of the residue with petroleum ether from silica gel $(90 \mathrm{~mL})$ afforded a viscous colorless oil; $0.98 \mathrm{~g}(71 \%) .{ }^{1} \mathrm{H}$ NMR: $\delta 7.45(\mathrm{~m}, 4 \mathrm{H}), 7.3(\mathrm{~m}, 3 \mathrm{H})$, 7.2 (m, $6 \mathrm{H}), 0.79$ (s, $7 \mathrm{H}), 0.05$ (s, $6 \mathrm{H}) .{ }^{13} \mathrm{C}$ NMR: $\delta 141.6,140.8$, $140.7,140.3,137.8,136.0,131.9,130.6,130.5,129.9,129.8$ (2 C), 127.8 (2 C), 127.4, 127.3, 127.3, 126.4, 17.5 (2 C), 13.6, -5.6 (2 C). MS $m / z(\%) 330\left(\mathrm{M}^{+}, 27\right), 287$ (100), 271 (25), 59 (33). Anal.: calcd for $\mathrm{C}_{23} \mathrm{H}_{26} \mathrm{Si}$ (330.54) C, 83.57; H, 7.93; found C, 83.34; $\mathrm{H}$, 8.00 .
\end{abstract}

3'-Isopropyldimethylsilyl-2-vinylbiphenyl (2). At $-75^{\circ} \mathrm{C}$, butyllithium $(1.4 \mathrm{mmol})$ in hexanes $(0.84 \mathrm{~mL})$ and, $5 \mathrm{~min}$ later, trimethyl borate $(0.62 \mathrm{~g}, 6.0 \mathrm{mmol})$ were added to 3-bromophenylisopropyldimethylsilane $(0.35 \mathrm{~g}, 1.4 \mathrm{mmol})$ in tetrahydrofuran $(10 \mathrm{~mL})$. The hexanes were stripped off and replaced by toluene $(10 \mathrm{~mL})$. 2-Bromostyrene $(0.16 \mathrm{~g}, 0.90 \mathrm{mmol})$, ethanol $(8.0 \mathrm{~mL})$, water $(3.0 \mathrm{~mL})$, potassium carbonate $(0.10 \mathrm{~g}, 0.94 \mathrm{mmol})$, and tetrakis[triphenylphosphine]palladium $(0)$ $(0.074 \mathrm{~g}, 0.064 \mathrm{mmol})$ were added. The mixture was heated to reflux for $2.5 \mathrm{~h}$ before being absorbed on silica gel $(5.0 \mathrm{~mL})$ which, when dry, was poured on top of a column filled with more silica gel $(75 \mathrm{~mL})$. Upon elution with hexanes, 2-vinyl-3'(isopropyldimethylsilyl)biphenyl was collected as a colorless oil; $0.14 \mathrm{~g}(54 \%)$. ${ }^{1} \mathrm{H}$ NMR: $\delta 7.7(\mathrm{~m}, 1 \mathrm{H}), 7.5(\mathrm{~m}, 2 \mathrm{H}), 7.41(\mathrm{t}, J=$ $6.6 \mathrm{~Hz}, 1 \mathrm{H}), 7.4(\mathrm{~m}, 4 \mathrm{H}), 6.74(\mathrm{dd}, J=17,11 \mathrm{~Hz}, 1 \mathrm{H}), 5.72(\mathrm{~d}$, $J=17 \mathrm{~Hz}, 1 \mathrm{H}), 5.20(\mathrm{~d}, J=11 \mathrm{~Hz}, 1 \mathrm{H}), 1.00(\mathrm{~s}, 7 \mathrm{H}), 0.29(\mathrm{~s}$, $6 \mathrm{H}) .{ }^{13} \mathrm{C}$ NMR: $\delta$ 141.1, 139.8, 138.2, 136.1, 135.9, 135.5, 132.7, 130.1, 127.6, 127.4, 127.3, 125.8, 114.5 (2 C), 17.4 (2 C), 13.8, -5.3 (2 C). MS: $m / z$ (\%) $280\left(\mathbf{M}^{+}, 1\right), 237$ (14), 195 (10), 178 (100), 165 (25), 101 (12), 59 (82). Anal.: calcd for $\mathrm{C}_{19} \mathrm{H}_{24} \mathrm{Si}$ (280.48) C, 81.36; $\mathrm{H}, 8.62$; found: $\mathrm{C}, 81.43$; $\mathrm{H}, 8.67$.

2-Cyano-3'-(isopropyldimethylsilyl)biphenyl (4). Analogously, from (3-bromophenyl)(isopropyl)dimethylsilane $(0.35 \mathrm{~g}$, $1.4 \mathrm{mmol})$ and 2-bromobenzonitrile $(0.16 \mathrm{~g}, 0.88 \mathrm{mmol})$, biphenylnitrile 4 was obtained as a colorless oil; $0.147 \mathrm{~g}(60 \%)$. ${ }^{1} \mathrm{H}$ NMR: $\delta 7.79(\mathrm{dd}, J=7.7,0.8 \mathrm{~Hz}, 1 \mathrm{H}), 7.7(\mathrm{~m}, 1 \mathrm{H}), 7.65(\mathrm{td}$, $J=7.8,1.4 \mathrm{~Hz}, 1 \mathrm{H}), 7.5(\mathrm{~m}, 5 \mathrm{H}), 0.99(\mathrm{~s}, 7 \mathrm{H}), 0.30(\mathrm{~s}, 6 \mathrm{H})$. ${ }^{13}$ C NMR: $\delta 145.8,139.4,137.3,134.2$ (2 C), 133.7, 132.7, 130.1, 129.0, 127.9, 127.4, 118.7, 111.4, 17.5 (2 C), 13.7, -5.3 (2 C). IR (chloroform): $v_{\max } 3016,2958,2874,2227 \mathrm{~cm}^{-1}$. MS: $\mathrm{m} / z$ (\%) 279 $\left(\mathrm{M}^{+}, 1\right), 264$ (2), 236 (100), 220 (23), 206 (16). Anal.: calcd for $\mathrm{C}_{18} \mathrm{H}_{21} \mathrm{NSi}$ (279.45) C, 77.36; H, 7.57; found: C, 77.41; H, 7.66.

2-Ethynyl-3'-(isopropyldimethylsilyl)biphenyl (3). At $-75^{\circ} \mathrm{C}$, butyllithium $(0.81 \mathrm{mmol})$ in hexanes $(0.50 \mathrm{~mL})$ was added to (2-bromophenylethynyl)trimethylsilane $(0.20 \mathrm{~g}, 0.80 \mathrm{mmol})$ in tetrahydrofuran. At $0{ }^{\circ} \mathrm{C}$, zinc bromide $(0.20 \mathrm{~g}, 0.89 \mathrm{mmol})$, and after stirring for $15 \mathrm{~min}$, 3-bromophenylisopropyldimethylsilane $(0.20 \mathrm{~g}, \quad 0.78 \mathrm{mmol})$ and tetrakis[triphenylphosphine]palladium(0) were consecutively added. The mixture was kept under reflux for $12 \mathrm{~h}$ before being absorbed on silica gel $(10 \mathrm{~mL})$. Elution with petroleum ether from a column filled with more silica $(0.10 \mathrm{~L})$ gave a viscous colorless oil; $0.160 \mathrm{~g}(72 \%) .{ }^{1} \mathrm{H}$ NMR: $\delta 7.78(\mathrm{~m}, 1 \mathrm{H}), 7.64$ (broad d, $J=7.8 \mathrm{~Hz}, 1 \mathrm{H}), 7.56$ (ddd, $J=7.6,1.9,1.4 \mathrm{~Hz}, 1 \mathrm{H}), 7.53(\mathrm{dt}, J=7.3,1.3 \mathrm{~Hz}, 1 \mathrm{H}), 7.4(\mathrm{~m}, 3$ H), 7.32 (ddd, $J=7.7,6.6,2.2 \mathrm{~Hz}, 1 \mathrm{H}), 3.03(\mathrm{~s}, 1 \mathrm{H}), 0.84(\mathrm{~s}, 7 \mathrm{H})$, 0.27 (s, 6 H). ${ }^{13} \mathrm{C}$ NMR: $\delta 144.7,139.2,138.1,135.0,133.9,133.4$, 133.1, 129.6, 129.4, 128.9, 127.3, 126.9, 120.4, 83.2, 80.0, 17.6 (2 C), 13.8, -5.3 (2 C). IR: $v_{\max } 3308,3012,2957,2881 \mathrm{~cm}^{-1}$. MS: $\mathrm{m} / \mathrm{z}$ (\%) $278\left(\mathrm{M}^{+}, 5\right), 235$ (99), 219 (100), 165 (8), 43 (6). Anal.: calcd for $\mathrm{C}_{19} \mathrm{H}_{22} \mathrm{Si}$ (278.46) C, 81.95; H, 7.96; found: $\mathrm{C}, 81.79 ; \mathrm{H}, 8.00$.

2-Formyl-3'-(isopropyldimethylsilyl)biphenyl $\quad$ 2-[3-(isopropyl)dimethylsilylphenyl|benzaldehyde $\} \quad$ (6). At $-75{ }^{\circ} \mathrm{C}$, tertbutyllithium $(0.66 \mathrm{mmol})$ in pentanes $(0.33 \mathrm{~mL})$ and azeotropically (using benzene) dried dimethylformamide $(0.10 \mathrm{~mL}, 0.094 \mathrm{~g}, 1.4 \mathrm{mmol})$ were added consecutively to 2-bromo-3'-(isopropyldimethylsilyl)biphenyl ${ }^{6}(0.22 \mathrm{~g}, 0.66 \mathrm{mmol})$ in tetrahydrofuran $(10 \mathrm{~mL})$. The mixture was absorbed on silica gel $(5 \mathrm{~mL})$ and eluted with a $1: 9(\mathrm{v} / \mathrm{v})$ mixture of diethyl ether and petroleum ether from a column filled with more silica gel $(50 \mathrm{~mL})$ to give a colorless oil; $0.105 \mathrm{~g}(62 \%) .{ }^{1} \mathrm{H}$ NMR: $\delta 9.98$ $(\mathrm{s}, 1 \mathrm{H}), 8.05(\mathrm{~d}, J=7.8 \mathrm{~Hz}, 1 \mathrm{H}), 7.64(\mathrm{td}, J=7.6$ and $1.4 \mathrm{~Hz}$, $1 \mathrm{H}), 7.56(\mathrm{dd}, J=7.2,0.8 \mathrm{~Hz}, 1 \mathrm{H}), 7.5(\mathrm{~m}, 4 \mathrm{H}), 7.38(\mathrm{dd}, J=$ 7.5, $1.3 \mathrm{~Hz}, 1 \mathrm{H}), 0.99(\mathrm{~s}, 7 \mathrm{H}), 0.27$ (s, $6 \mathrm{H}) .{ }^{13} \mathrm{C}$ NMR: $\delta 192.4$, 146.3, 139.2, 136.8, 135.5, 133.8, 137.7, 133.5, 130.8, 130.4, 127.7, 127.6, 127.5, 17.5 (2 C), 13.7, -5.4 (2 C). IR: $v_{\max } 3020,2957$, 2865, $1691 \mathrm{~cm}^{-1}$. MS: $m / z(\%) 282\left(\mathrm{M}^{+}, 3\right), 239$ (14), 165 (100). 
Anal.: calcd for $\mathrm{C}_{18} \mathrm{H}_{22} \mathrm{OSi}$ (282.45) C, 76.54; $\mathrm{H}, 7.85$; found: $\mathrm{C}$, 76.40; H, 7.94.

2-Hydroxymethyl-3'-(isopropyldimethylsilyl)biphenyl $\{2-[3-$ (isopropyldimethylsilyl)phenyl]benzyl alcohol\} (5). Aldehyde 6 $(0.20 \mathrm{~g}, 0.71 \mathrm{mmol})$ was treated with sodium borohydride $(0.027 \mathrm{~g}$, $0.71 \mathrm{mmol})$ in methanol $(10 \mathrm{~mL})$ at $+25^{\circ} \mathrm{C}$ for $1 \mathrm{~h}$. Diethyl ether $(10 \mathrm{~mL})$ was added and the solution was washed with $0.1 \mathrm{M}$ sulfuric acid $(5.0 \mathrm{~mL})$. Absorption of the organic layer on silica gel $(10 \mathrm{~mL})$ and elution with a $1: 4(\mathrm{v} / \mathrm{v})$ mixture of diethyl ether and hexanes from a column filled with more silica $(0.10 \mathrm{~L})$ to give a colorless oil; $0.192 \mathrm{~g}(95 \%) .{ }^{1} \mathrm{H}$ NMR: $\delta 7.57(\mathrm{dd}, J=7.0$, $1.5 \mathrm{~Hz}, 1 \mathrm{H}), 7.51(\mathrm{dt}, J=7.1,1.3 \mathrm{~Hz}, 1 \mathrm{H}), 7.5(\mathrm{~m}, 1 \mathrm{H}), 7.4(\mathrm{~m}$, $4 \mathrm{H}), 7.30$ (dd, $J=7.2,1.7 \mathrm{~Hz}, 1 \mathrm{H}), 4.62(\mathrm{~s}, 2 \mathrm{H}), 0.96(\mathrm{~s}, 7 \mathrm{H})$, 0.26 (s, 6 H). ${ }^{13} \mathrm{C}$ NMR: $\delta 141.6,139.6,138.7,138.1,134.6,132.8$, $130.1,129.4,128.3,127.6$ (2 C), 127.5, 63.2, 17.6 (2 C), 13.7, -5.33 (2 C). IR: $v_{\max } 3315,2953,2880,1209 \mathrm{~cm}^{-1}$. MS: $\mathrm{m} / z(\%) 284\left(\mathrm{M}^{+}\right.$, 3), 165 (20), 75 (100), 43 (10). Anal.: calcd for $\mathrm{C}_{18} \mathrm{H}_{24} \mathrm{OSi}$ (284.47) C, 76.00; H, 8.50; found C, 75.99; $\mathrm{H}, 8.69$.

\section{2-Carboxy-3'-(isopropyldimethylsilyl)biphenyl $\quad\{$ 2-[3-(isopro- pyldimethylsilyl)phenyl]benzoic acid $\} \quad$ (7). Butyllithium $(0.81 \mathrm{mmol})$ in hexanes $(0.50 \mathrm{~mL})$ was added to 2-bromo- $3^{\prime}$-(isopropyldimethylsilyl)biphenyl $(0.27 \mathrm{~g}, \quad 0.81 \mathrm{mmol})$ in tetrahydrofuran $(5.0 \mathrm{~mL})$ at $-75^{\circ}$. The mixture was immediately poured onto an excess of freshly crushed dry ice, the cold bath was removed and the temperature was allowed to rise to $+25^{\circ} \mathrm{C}$. The pale yellow solid left behind after evaporation of the solvent was washed with diethyl ether $(3 \times 5 \mathrm{~mL})$ and $0.1 \mathrm{M}$ sulfuric acid $(10 \mathrm{~mL})$. The colorless solid was recrystallized from petroleum ether to give white needles; $\mathrm{mp} 89-91{ }^{\circ} \mathrm{C} ; 0.152 \mathrm{~g}(63 \%) .{ }^{1} \mathrm{H}$ NMR: $\delta 7.92(\mathrm{dd}, J=7.7,1.2 \mathrm{~Hz}, 1 \mathrm{H}), 7.57(\mathrm{td}, J=7.5,0.9 \mathrm{~Hz}$, $1 \mathrm{H}), 7.4(\mathrm{~m}, 6 \mathrm{H}), 0.93(\mathrm{~s}, 7 \mathrm{H}), 0.24(\mathrm{~s}, 6 \mathrm{H}) ;{ }^{13} \mathrm{C}$ NMR: $\delta$ 173.3, 143.5, 140.0, 138.3, 134.2, 132.9, 131.9, 131.2, 130.5, 129.5, 128.7, 127.3, 127.0, 17.5 (2 C), 13.7, -5.4 (2 C). IR : $v_{\max } 3013$ (very broad), 2957, 2865, $1722 \mathrm{~cm}^{-1}$. Anal.: calcd for $\mathrm{C}_{18} \mathrm{H}_{22} \mathrm{O}_{2} \mathrm{Si}$ (298.45) C, 72.44; H, 7.43; found C, 72.89; H, 8.03.}

2-Methoxycarbonyl-3'-(isopropyldimethylsilyl)biphenyl \{methyl 2-[3-(iso-propyldimethylsilyl)phenyl]benzoic acid\} (8). Ethereal diazomethane was added dropwise to the acid $7(0.10 \mathrm{~g} 0.33 \mathrm{mmol})$, dissolved in diethyl ether $(5 \mathrm{~mL})$, until the yellow color persisted. Elution with a $1: 9(\mathrm{v} / \mathrm{v})$ mixture of diethyl ether and hexanes from silica gel $(90 \mathrm{~mL})$ gave a viscous colorless oil; $0.093 \mathrm{~g}(89 \%) .{ }^{1} \mathrm{H}$ NMR: $\delta 7.81$ (dd, $J=7.2,1.4 \mathrm{~Hz}, 1 \mathrm{H}), 7.52(\mathrm{td}, J=7.3,1.1 \mathrm{~Hz}, 1$ $\mathrm{H}), 7.48(\mathrm{dt}, J=7.4,1.2 \mathrm{~Hz}, 1 \mathrm{H}), 7.4(\mathrm{~m}, 4 \mathrm{H}), 7.33(\mathrm{dt}, J=7.6$, $1.4 \mathrm{~Hz}, 1 \mathrm{H}), 3.61$ (s, $3 \mathrm{H}), 0.96$ (s, $7 \mathrm{H}), 0.25(\mathrm{~s}, 6 \mathrm{H}) .{ }^{13} \mathrm{C}$ NMR: $\delta$ 169.3, 142.6, 140.3, 138.3, 133.8, 132.8, 131.6, 131.1, 130.7, 129.6, 128.6, 127.3, 127.0, 51.9, 17.5 (2 C), 13.7, -5.3 (2 C). MS: $m / z(\%)$ $312\left(\mathrm{M}^{+}, 7\right), 269$ (53), 237 (57), 195 (44), 89 (100), 59 (25). Anal.: calcd for $\mathrm{C}_{19} \mathrm{H}_{24} \mathrm{O}_{2} \mathrm{Si}$ (312.48) C, 73.03; H, 7.74; found, C, 72.94; $\mathrm{H}, 7.77$.

3'-(Isopropyldimethylsilyl)-2-(pentafluorophenyl)biphenyl $\left\{\mathbf{3}^{\prime}\right.$ (isopropyl)dimethylsilyl-2,3,4,5,6-pentafluoro- $1,1^{\prime} ; \mathbf{2}^{\prime}, \mathbf{1}^{\prime}$ terphenyl $\}$ (9). At $-75^{\circ} \mathrm{C}$, butyllithium $(0.49 \mathrm{mmol})$ in hexanes $(0.30 \mathrm{~mL})$ and, $5 \mathrm{~min}$ later, pentafluorobenzene $(0.10 \mathrm{~g}, 0.54 \mathrm{mmol})$ were added to 2-bromo-3'-(isopropyldimethylsilyl)biphenyl (0.16 g, $0.48 \mathrm{mmol})$ in tetrahydrofuran $(10 \mathrm{~mL})$. The mixture was kept for $1 \mathrm{~h}$ at $+25^{\circ} \mathrm{C}$ before being absorbed on silica $(5 \mathrm{~mL})$. Elution with petroleum ether from silica gel $(50 \mathrm{~mL})$ gave a colorless oil; b.p. $180-185^{\circ} \mathrm{C} / 0.2 \mathrm{mmHg}$ (Hickmann flask); $0.115 \mathrm{~g}(57 \%)$. ${ }^{1} \mathrm{H}$ NMR: $\delta 7.5$ (m, $\left.3 \mathrm{H}\right), 7.3(\mathrm{~m}, 5 \mathrm{H}), 0.83$ (s, $\left.7 \mathrm{H}\right), 0.14$ (s, 6 $\mathrm{H}) ;{ }^{13} \mathrm{C}$ NMR: $\delta 144.0$ (broad d, $J=241 \mathrm{~Hz}$ ), 143.3, 140.5 (bd, $J=252 \mathrm{~Hz}, 2 \mathrm{C}), 139.4,138.3,137.3(\mathrm{dt}, J=251,16 \mathrm{~Hz}), 133.9$, $132.9,131.0,130.3,129.7,128.9,127.5,127.4,125.0,116.0$ (t, $J=$ $22 \mathrm{~Hz}), 17.2(2 \mathrm{C}), 13.7,-5.6(2 \mathrm{C}) .{ }^{19} \mathrm{~F}$ NMR: $\delta-140.58(\mathrm{dd}, J=$ 23 and $8.0 \mathrm{~Hz}, 2 \mathrm{~F}),-156.27$ (t, $J=22 \mathrm{~Hz}, 1 \mathrm{~F}),-163.28(\mathrm{td}, J=$ $22,7.0 \mathrm{~Hz}, 2$ F). MS: $m / z(\%) 420\left(\mathrm{M}^{+}, 15\right), 377$ (100), 280 (79), 262 (32), 77 (43), 43 (10). Anal.: calcd for $\mathrm{C}_{23} \mathrm{H}_{21} \mathrm{~F}_{5} \mathrm{Si}$ (420.49) C, 65.70; H, 5.03; found: C, 66.62; H, 5.18.

2-(Hexafluoro-a-hydroxyisopropyl)-3' -(isopropyldimethylsilyl)biphenyl \{2-[3-(isopropyldimethylsilyl)phenyl]-1-[2,2,2-trifluoro-1(trifluoromethyl)ethanol $\}$ (10). Gaseous hexafluoroacetone was generated by adding cautiously the trihydrate to concentrated (98\% aq.) sulfuric acid at $+50^{\circ} \mathrm{C}$ and it was condensed, through Teflon tubing, into a $50 \mathrm{~mL}$ Schlenk tube cooled to $-75^{\circ} \mathrm{C}$. In a second Schlenk tube, butyllithium $(0.60 \mathrm{mmol})$ in hexanes $(0.37 \mathrm{~mL})$ was added dropwise, in $15 \mathrm{~min}$, to a solution of 2bromo-3'-(isopropyldimethylsilyl)biphenyl $(0.20 \mathrm{~g}, 0.60 \mathrm{mmol})$ in tetrahydrofuran $(10 \mathrm{~mL})$ at $-95^{\circ} \mathrm{C}$. Warming the Schlenk tube slowly to $+25{ }^{\circ} \mathrm{C}$ made the hexafluoroacetone stream through a Teflon cannula, ending at $5 \mathrm{~mm}$ above the liquid surface, into the second Schlenk tube containing the reaction intermediate. When the addition was complete, the mixture was kept for further $10 \mathrm{~min}$ at $-95^{\circ} \mathrm{C}$. Upon chromatography on silica gel $(70 \mathrm{~mL})$, using a $1: 20(\mathrm{v} / \mathrm{v})$ mixture of diethylether and hexanes as the eluent, a viscous colorless oil was collected; $0.169 \mathrm{~g}(67 \%) .{ }^{1} \mathrm{H}$ NMR: $\delta 7.76$ (broad d, $J=3.9 \mathrm{~Hz}, 1 \mathrm{H}), 7.58(\mathrm{dd}, J=6.1,1.2 \mathrm{~Hz}, 1 \mathrm{H}), 7.4(\mathrm{~m}$, $4 \mathrm{H}), 7.35(\mathrm{~d}, J=7.5 \mathrm{~Hz}, 1 \mathrm{H}), 7.2(\mathrm{~m}, 1 \mathrm{H}), 3.52(\mathrm{~s}, 1 \mathrm{H}), 0.94(\mathrm{~s}$, $7 \mathrm{H}), 0.25(\mathrm{~s}, 3 \mathrm{H}), 0.24(\mathrm{~s}, 3 \mathrm{H}) .{ }^{13} \mathrm{C}$ NMR: $\delta$ 141.6, 139.8, 138.7, 134.2 (2 C), 133.3, 129.3, 129.1, 128.0 (sept, $J=3.1 \mathrm{~Hz}$ ), 127.9, $127.8,126.5,122.6$ (q, $J=285 \mathrm{~Hz}, 2 \mathrm{C}), 80.1(\mathrm{q}, J=29 \mathrm{~Hz}), 17.3$ (2 C), 13.6, -5.5 (2 C). ${ }^{19} \mathrm{~F}$ NMR: $\delta-75.14(\mathrm{q}, J=8.3 \mathrm{~Hz}, 3 \mathrm{~F})$, -75.71 (q, $J=8.3 \mathrm{~Hz}, 3 \mathrm{~F})$. MS: $m / z(\%) 420\left(\mathrm{M}^{+}, 1\right), 377(15), 233$ (100), 214 (47), 183 (78), 165 (28), 77 (60), 43 (17). Anal.: calcd for $\mathrm{C}_{20} \mathrm{H}_{22} \mathrm{~F}_{6} \mathrm{OSi}$ (420.46) C, 57.13; H, 5.27; found: C, 56.33; H, 5.48.

2-Formyl-3'-(isopropyldimethylsilyl)biphenyl $\quad$ 2-[3-(isopropyl)dimethylsilylphenyl]benzaldehyde $\}$ (6). Ethanol $(3.0 \mathrm{~mL})$, benzene $(5.0 \mathrm{~mL})$, (3-bromophenyl)isopropyldimethylsilane ${ }^{6}(0.20 \mathrm{~g}$, $0.78 \mathrm{mmol}), 2.0 \mathrm{M}$ aq. potassium carbonate $(1.6 \mathrm{~mL})$, tetrakis[triphenylphosphine] palladium $(0)(0.040 \mathrm{~g}, 0.034 \mathrm{mmol})$ were added consecutively to 2-formylphenylboronic acid $(0.13 \mathrm{~g}$, $0.86 \mathrm{mmol})$. After reflux for $3 \mathrm{~h}$, the mixture was eluted with petroleum ether from silica gel $(50 \mathrm{~mL})$ to furnish a viscous colorless oil; $0.200 \mathrm{~g}(91 \%)$. Spectroscopic and analytical data are given in the appropriate section above.

3'-Isopropyldimethylsilyl-2-(trifluoromethyl)biphenyl (11). (3Bromophenyl)isopropyldimethylsilane $(0.20 \mathrm{~g}, 0.78 \mathrm{mmol})$ and 2-trifluoromethylboronic acid $(0.18 \mathrm{~g}, 0.95 \mathrm{mmol})$ were subjected to the same procedure as described above for the preparation of aldehyde 6. Hickmann distillation of the residue provided a colorless oil; b.p. $151-153^{\circ} \mathrm{C} / 0.2 \mathrm{mmHg} ; 0.201 \mathrm{~g}(80 \%) .{ }^{1} \mathrm{H}$ NMR: $\delta 7.76(\mathrm{~d}, J=7.8 \mathrm{~Hz}, 1 \mathrm{H}), 7.4(\mathrm{~m}, 7 \mathrm{H}), 0.96(\mathrm{~s}, 7 \mathrm{H}), 0.26(\mathrm{~s}, 6 \mathrm{H})$. ${ }^{13}$ C NMR: $\delta 141.8,138.9,138.0,134.4,133.1,132.0,131.2,129.2$, $128.5(\mathrm{q}, J=29 \mathrm{~Hz}), 127.2,126.9,126.0(\mathrm{q}, J=5.3 \mathrm{~Hz}), 124.1(\mathrm{q}$, $J=272 \mathrm{~Hz}), 17.5$ (2 C), 13.8, $-5.4(2 \mathrm{C}) .{ }^{19} \mathrm{~F}$ NMR: $\delta-57.19$ (s). MS: $m / z(\%) 322$ (M+ $\left.\mathbf{M}^{+}, 67\right), 279$ (99), 201 (64), 183 (100), 163 (58), 
133 (20), 77 (100), 43 (34). Anal.: calcd for $\mathrm{C}_{18} \mathrm{H}_{21} \mathrm{~F}_{3} \mathrm{Si}(322.44) \mathrm{C}$, 67.05; H, 6.56; found $\mathrm{C}, 67.21 ; \mathrm{H}, 6.60$.

3'-Isopropyldimethylsilyl-2-(trifluoromethoxy)biphenyl (12). Analogously prepared from 3-bromophenylisopropyldimethylsilane $(0.19 \mathrm{~g}, 0.75 \mathrm{mmol})$ and 2-(trifluoro-methoxy)phenylboronic acid $(0.18 \mathrm{~g}, 0.90 \mathrm{mmol})$; b.p. $156-158{ }^{\circ} \mathrm{C} / 0.2 \mathrm{mmHg}$; $0.223 \mathrm{~g}(88 \%) .{ }^{1} \mathrm{H}$ NMR: $\delta 7.62$ (broad s, $\left.1 \mathrm{H}\right), 7.45$ (m, $\left.1 \mathrm{H}\right), 7.37$ $(\mathrm{m}, 3 \mathrm{H}), 0.99(\mathrm{~s}, 7 \mathrm{H}), 0.28(\mathrm{~s}, 6 \mathrm{H}) .{ }^{13} \mathrm{C} \mathrm{NMR}$ : $\delta 146.3,138.6$, $135.9,135.6,134.8,133.2,131.5,129.5,128.5,127.5,127.0,121.2$, 120.4 (q, $J=256 \mathrm{~Hz}), 14.4$ (2 C), 13.7, -5.4 (2 C). ${ }^{19} \mathrm{~F}$ NMR: $\delta$ -57.47 (s). MS: $m / z$ (\%) $338\left(\mathrm{M}^{+}, 10\right), 199$ (100), 165 (50), 152 (44), 77 (89), 43 (14). Anal.: calcd for $\mathrm{C}_{18} \mathrm{H}_{21} \mathrm{~F}_{3} \mathrm{OSi}$ (338.44) C, 63.88; H, 6.25; found: C, 64.03; H, 6.38.

\section{Variable Temperature NMR Studies}

NMR spectra were performed using a Varian INOVA spectrometer operating at a field of 14.4 Tesla. The variable temperature experiments of compound $\mathbf{1 0}$ were recorded in acetonitrile- $d_{3}$. In the other cases, where the temperature was to be decreased below $-100{ }^{\circ} \mathrm{C}$, the NMR tubes containing the compound were manipulated at a vacuum line. First a small amount (approx. $0.05 \mathrm{~mL}$ ) of hexadeuterobenzene (or acetone- $d_{6}$ in the case of compound 7) was introduced by means of a microsyringe for locking purposes. The NMR tube was immersed in liquid nitrogen and evacuated in order to condense about $0.45 \mathrm{~mL}$ of chlorodifluoromethane (Freon 22) and about $0.15 \mathrm{~mL}$ of dichlorofluoromethane (Freon 21) transferred as gases from lecture bottles. The tubes were subsequently sealed under reduced pressure (0.01 mbar) using a methane/oxygen torch. Avoiding any rapid temperature change, the samples were cautiously warmed to $+25^{\circ} \mathrm{C}$, where the Freons develop a pressure of about 8 atm. After a few hours at ambient temperature, the samples can be safely introduced into the probe head of the spectrometer, already cooled to $-30{ }^{\circ} \mathrm{C}$. Low temperature $600 \mathrm{MHz}{ }^{1} \mathrm{H}$ spectra (compounds 2 , $5,6,7,8,9,10,11$ ) were acquired without spinning using a $5 \mathrm{~mm}$ dual direct probe with a $9000 \mathrm{~Hz}$ sweep width, $2.0 \mu \mathrm{s}\left(20^{\circ}\right.$ tip angle) pulse width, $3 \mathrm{~s}$ acquisition time and $1 \mathrm{~s}$ delay time. A shifted sine bell weighting function ${ }^{31}$ equal to the acquisition time (i.e., $3 \mathrm{~s}$ ) was applied before the Fourier transformation. Usually 32 to 64 scans were collected. Low temperature $150.8 \mathrm{MHz}{ }^{13} \mathrm{C}$ spectra (compounds $\mathbf{1}, \mathbf{3}, \mathbf{4}, \mathbf{7}, \mathbf{1 2}$ ) were acquired without spinning and under proton decoupling conditions with a $38000 \mathrm{~Hz}$ sweep width, $4.2 \mu$ s ( $60^{\circ}$ tip angle) pulse width, $1 \mathrm{~s}$ acquisition time and $1 \mathrm{~s}$ delay time. A line broadening function of $1-2 \mathrm{~Hz}$ was applied before the Fourier transformation. Usually 128 to 512 scans were collected.

When operating the NMR apparatus at low temperature, a flow of dry nitrogen first passed through a precooling unit adjusted to $-50{ }^{\circ} \mathrm{C}$. Then the gas entered into an inox steel heat-exchanger immersed in liquid nitrogen and connected to the NMR probe head by a vacuum-insulated transfer line. Gas flows of 10 to $40 \mathrm{~L} \mathrm{~min}^{-1}$ were required to descend to the desired temperature. Temperature calibrations were performed before the experiments, using a digital thermometer and a $\mathrm{Cu} / \mathrm{Ni}$ thermocouple (models C9001 and KX2384, respectively, Comark Ltd., Hertfordshire, $\mathrm{UK}$ ) placed in an NMR tube filled with isopentane. The conditions were kept as identical as possible with all subsequent work. In particular, the sample was not spun and the gas flow was the same as that used during the acquisition of the spectra. The uncertainty in temperature measurements can be estimated as $\pm 2{ }^{\circ} \mathrm{C}$.

Line shape simulations were performed using a $\mathrm{PC}$ version of the QCPE DNMR6 program. ${ }^{32}$ Electronic superimposition of the original spectrum and of the simulated one enabled the determination of the most reliable rate constant. The rate constants, thus obtained at various temperatures, afforded the free energy of activation $\Delta G^{\ddagger}$ or bond rotation by applying the Eyring equation. ${ }^{33}$ In all cases investigated, the activation energy $\Delta G^{\star}$ was found to be virtually invariant in the given temperature range, thus implying a negligible activation entropy $\Delta S^{\ddagger} .{ }^{34}$

\section{Computational Work}

A complete conformational search was preliminarily carried out by means of the Molecular Mechanics Force Field (MMFF), ${ }^{35}$ using the Monte-Carlo method implemented in the package TITAN 1.0.5. ${ }^{36}$ The most stable conformers thus identified were subsequently energy-minimized by Density Functional Theory (DFT) computations. Those were performed by the Gaussian

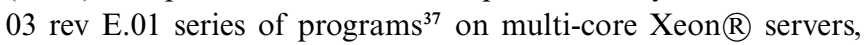
the operating system being the Red Hat Enterprise Linux 5.1. The standard geometry optimization included in Gaussian 03 is the "Berny algorithm". ${ }^{38}$ This algorithm uses the various forces acting on the atoms of a given structure along with the Hessian to predict energetically more favorable structures and thus to optimize the molecular structure towards the nearest local minimum on the potential energy surface. To avoid the computationally expensive explicit calculation of the second derivative matrix, the Berny algorithm constructs an approximate Hessian at the beginning of the optimization procedure through application of a simple valence force field, and then uses the energies and first derivatives calculated along the optimization pathway to upgrade the approximate Hessian matrix. All the calculations employed the B3LYP hybrid HF-DFT method ${ }^{39}$ and the 6-31G(d) basis sets.

Harmonic vibrational frequencies were calculated for all stationary points. As revealed by the frequency analysis, imaginary frequencies were absent in all ground states whereas just one imaginary frequency was associated with each transition state. Visual inspection of the corresponding normal modes ${ }^{40}$ validated the identification of the transition states.

The listed energy values (see Table 2) represent total electronic energies. In general, these give the best fit with experimental DNMR data. ${ }^{41}$ Therefore, the computed numbers have not been corrected for zero-point energy contributions or other thermodynamic parameters. This avoids artifacts that might result from the ambiguous choice of an adequate reference temperature, from empirical scaling factors to which one has often to resort for a better matching of experimental and theoretical numbers ${ }^{42}$ and from the idealization of low-frequency vibrators as harmonic oscillators (particularly important in the present case, where one third of the calculated frequencies fall in the $500-600 \mathrm{~cm}^{-1}$ range). ${ }^{43}$

\section{Acknowledgements}

The authors are indebted to the University of Bologna (RFO funds 2008), the Ministero dell'Università e Ricerca, Roma (MUR PRIN 2004 contract 033322 ), and the Schweizerische Nationalfonds zur 
Förderung der Wissenschaftlichen Forschung, Bern (grant 20100'336-02) for financial support.

\section{Notes and references}

1 R. Gallo, Prog. Phys. Org. Chem., 1983, 14, 115-163.

2 A. Almenningen, O. Bastiansen, L. Fernholt, B. N. Cyvin, S. J. Cyvin and S. Samdal, J. Mol. Struct., 1985, 128, 59-76.

3 O. Bastiansen and S. Samdal, J. Mol. Struct., 1985, 128, 115-125.

4 F. Grein, J. Phys. Chem. A, 2002, 106, 3823-3827.

5 M. P. Johansson and J. Olsen, J. Chem. Theory Comput., 2008, 4, 14601471.

6 R. Ruzziconi, S. Spizzichino, L. Lunazzi, A. Mazzanti and M. Schlosser, Chem. Eur. J., 2009, 15, 2645-2652.

7 A. Mazzanti, L. Lunazzi, R. Ruzziconi, S. Spizzichino and M. Schlosser, Chem. Eur. J., 2010, 16, 9186-9192.

8 G. Bott, L. D. Field and S. Sternhell, J. Am. Chem. Soc., 1980, 102, $5618-5626$.

9 S. Kotha, K. Lahiri and K. Dhurke, Tetrahedron, 2002, 58, 9633-9695.

10 N. T. S. Phan, M. Van Der Sluys and C. W. Jones, Adv. Synth. Catal., 2006, 348, 609-679.

11 S. K. Collins, G. P. A. Yap and A. G. Fallis, Angew. Chem., 2000, 112, 393-396; S. K. Collins, G. P. A. Yap and A. G. Fallis, Angew. Chem., Int. Ed., 2000, 39, 385-388.

12 A. Mazzanti, L. Lunazzi, M. Minzoni and J. E. Anderson, J. Org. Chem., 2006, 71, 5474-5481.

13 B. E. Smart, Organofluorine Chemistry : Principles and Commercial Applications, R. E. Banks, B. E. Smart and J. C Tatlow ed., Plenum Press, New York, 1994, pp 57-88, spec. pp 81-82.

14 J. A. Hirsch, Top. Stereochem., 1967, 1, 199-222.

15 C. H. Bushweller, in Conformational Behavior of Six-Membered Rings : Analysis, Dynamics and Stereoelectronic Effects, ed. E. Juaristi, VCH, New York, 1995, pp 25-58.

16 E. L. Eliel and S. H. Wilen, Stereochemistry of Organic Compounds, Wiley, New York, 1994, pp 690-700.

17 E. W. Della, J. Am. Chem. Soc., 1967, 89, 5221-5224.

18 H. Booth and J. R. Everett, J. Chem. Soc., Perkin Trans. 2, 1980, 255259.

19 G. Schultz, I. Hargittai and R. Seip, Z. Naturforsch. A, 1981, 36, 669673.

20 R. Seip, G. Schultz, I. Hargittai and Z. G. Szabó, Z. Naturforsch. A, 1977, 32, 1178-1183.

21 F. Leroux, P. Jeschke and M. Schlosser, Chem. Rev., 2005, 105, 827-856.

22 D. Federsel, A. Herrmann, D. Christen, S. Sander, H. Willner and H. Oberhammer, J. Mol. Struct., 2001, 567-568, 127-136.

23 I. F. Shishkov, H. J. Geise, C. Van Alsenoy, L. V. Khristenko, L. V. Vilkov, V. M. Senyavian, B. Van Der Veken, W. Herrebout, B. V. Lokshin and O. G. Garkusha, J. Mol. Struct., 2001, 567-568, 339-360.

24 Enantiocontrolled Synthesis of Fluoro-Organic Compounds, ed. V. A. Soloshonok, Wiley, Chichester, 1999.

25 Organofluorine Compounds:Chemistry and Applications, ed. T. Hiyama, Springer, Berlin, 2000.

26 P. Maienfisch, Chimia, 2004, 58, 92-92.
27 P. Maienfisch and R. G. Hall, Chimia, 2004, 58, 93-99.

28 J. D. Dunitz, ChemBio Chem, 2004, 5, 614-621.

29 H.-J. Böhm, D. Banner, S. Bendels, M. Kansy, B. Kuhn, K. Müller, U. Obst-Sander and M. Stahl, ChemBioChem, 2004, 5, 637-643.

30 M. Schlosser, Angew. Chem., 2006, 118, 5558-5572; M. Schlosser, Angew. Chem., Int. Ed., 2006, 45, 5432-5446.

31 T. D. W. Claridge, High-Resolution NMR Techniques in Organic Chemistry, Pergamon, Oxford, 1999, p. 71.

32 J. H. Brown and C. H. Bushweller, DNMR6: Calculation of NMR Spectra Subject to the Effects of Chemical Exchange, (program 633) QCPE Bulletin, Bloomington, Indiana, 1983, 3, 103-103.

33 H. Eyring, Chem. Rev., 1935, 17, 65-77.

34 (a) S. Hoogasian, C. H. Bushweller, W. G. Anderson and G. Kingsley, J. Phys. Chem., 1976, 80, 643-648; (b) L. Lunazzi, G. Cerioni and K. U. Ingold, J. Am. Chem. Soc., 1976, 98, 7484-7488; (c) M. A. Cremonini, L. Lunazzi, G. Placucci, R. Okazaki and G. Yamamoto, J. Am. Chem. Soc., 1990, 112, 2915-2921; (d) D. Casarini, C. Rosini, S. Grilli, L. Lunazzi and A. Mazzanti, J. Org. Chem., 2003, 68, 1815-1820; (e) L. Lunazzi, M. Mancinelli and A. Mazzanti, J. Org. Chem., 2007, 72, 5391-5394; (f) D. Casarini, L. Lunazzi and A. Mazzanti, Eur. J. Org. Chem., 2010, 2035-2056.

35 T. A. Halgren, J. Comput. Chem., 1996, 17, 490-519.

36 Package TITAN 1.0.5, Wavefunction Inc., Irvine, CA.

37 Gaussian 03, Revision E.01, M. J. Frisch, G. W. Trucks, H. B. Schlegel, G. E. Scuseria, M. A. Robb, J. R. Cheeseman, J. A. Montgomery, T. Vreven, K. N. Kudin, J. C. Burant, J. M. Millam, S. S. Iyengar, J. Tomasi, V. Barone, B. Mennucci, M. Cossi, G. Scalmani, N. Rega, G. A. Petersson, H. Nakatsuji, M. Hada, M. Ehara, K. Toyota, R. Fukuda, J. Hasegawa, M. Ishida, T. Nakajima, Y. Honda, O. Kitao, H. Nakai, M. Klene, X. Li, J. E. Knox, H. P. Hratchian, J. B. Cross, V. Bakken, C. Adamo, J. Jaramillo, R. Gomperts, R. E. Stratmann, O. Yazyev, A. J. Austin, R. Cammi, C. Pomelli, J. W. Ochterski, P. Y. Ayala, K. Morokuma, G. A. Voth, P. Salvador, J. J. Dannenberg, V. G. Zakrzewski, S. Dapprich, A. D. Daniels, M. C. Strain, O. Farkas, D. K. Malick, A. D. Rabuck, K. Raghavachari, J. B. Foresman, J. V. Ortiz, Q. Cui, A. G. Baboul, S. Clifford, J. Cioslowski, B. B. Stefanov, G. Liu, A. Liashenko, P. Piskorz, I. Komaromi, R. L. Martin, D. J. Fox, T. Keith, M. A. Al-Laham, C. Y. Peng, A. Nanayakkara, M. Challacombe, P. M. W. Gill, B. Johnson, W. Chen, M. W. Wong, C. Gonzalez and J. A. Pople, Gaussian Inc., Wallingford CT, 2004.

38 C. Peng, P. Y. Ayala, H. B. Schlegel and M. J. Frisch, J. Comput. Chem., 1996, 17, 49-56.

39 C. Lee, W. Yang and R. G. Parr, Phys. Rev. B: Condens. Matter, 1988, 37, 785-789; A. D. Becke, J. Chem. Phys., 1993, 98, 5648-5652; P. J. Stephens, F. J. Devlin, C. F. Chabalowski and M. J. Frisch, J. Phys. Chem., 1994, 98, 11623-11627.

40 Package Gauss View 4.1.2, Gaussian Inc., Wallingford CT, 2006.

41 P. Y. Ayala and H. B. Schlegel, J. Chem. Phys., 1998, 108, 2314 2325.

42 C. F. Tormena, R. Rittner, R. J. Abraham, E. A. Basso and B. C. Fiorin, J. Phys. Org. Chem., 2004, 17, 42-48.

43 M. W. Wong, Chem. Phys. Lett., 1996, 256, 391-399; S. E. Wheeler, A. J. McNeil, P. Müller, T. M. Swager and K. N. Houk, J. Am. Chem. Soc., 2010, 132, 3304-3311. 